READERS' OPINION AND DISCUSSION

OPINION

\section{Leishmania infantum versus Leishmania chagasi: do not forget the law of priority}

\section{FilipeDantas-Torres}

Departamento de Imunologia, Centro de Pesquisas Aggeu

Magalhães-Fiocruz, Av. Professor Moraes Rego s/n, 50670420 Recife, PE, Brasil

\section{Dear Editor,}

Lainson and Rangel (2005) have recently published a consistent review on Lutzomyia longipalpis (Diptera: Psychodidae) and visceral leishmaniasis (VL) in the Americas, with particular attention to the eco-epidemiology of disease in Brazil. In their review, they have discussed with property the taxonomic position and origin of the causal agent of the disease. However, I would like to add some comments on this issue, especially in relation to the nomenclature of the parasite.

VL is far the most severe form of leishmaniasis and it is often lethal if untreated (Desjeux 2004, Dujardin 2005). In the Americas and the Mediterranean region, the disease is a zoonosis caused by Leishmania infantum (Alvar et al. 2004), an obligatory intracellular protozoan first described in 1908 (Nicolle 1908). However, since Cunha and Chagas (1937) described L. chagasi as a new species responsible for the disease in the Americas, the nomenclature and, particularly, the origin of the causal agent of VL in those areas have been subjects to much debate and speculation. The controversy started a year after the description of L. chagasi, when Cunha (1938) himself concluded that the agent of VL in the Americas is identical to L. infantum. In the late 1990s, a further study using methods such as random amplification of polymorphic DNA (RAPD), DNA sequence analysis of the major surface protease (gp63) and hybridization with the DNA probe Lmet9, upon isolates from different geographical and host origins, was not able to distinguish $L$. chagasi from $L$. infantum (Maurício et al. 1999). On the other hand, based on minor phenotypic and genotypic differences (Santoro et al. 1984, Lainson \& Shaw 1987, Palatnik et al. 1990, Ellis \& Crampton 1991, Gramiccia et al. 1992), some authors have separated L. infantum and L. chagasi into two species. Others have also believed that these parasites are different, but have decided to separate them into two subspecies. In this case, the names L. infantum infantum and L. i. chagasi have been used (Lainson \& Rangel 2005).

Corresponding author: fdt@cpqam.fiocruz.br Postgraduate studentship from $\mathrm{CNPq}$
Interestingly, the discussion on the nomenclature of the causal agent of VL in the Americas and the Mediterranean region has been influenced by other important discussion: the origin of the parasite. Some authors believe that $L$. chagasi is synonymous with $L$. infantum, which was imported from Europe during the Portuguese and Spanish colonization (Killick-Kendrick 1985, Rioux et al. 1990). Others, however, believe that L. chagasi would have been present in the Americas before the European colonization (Lainson \& Rangel 2005). Indeed, both hypotheses are similarly plausible. Thus, the discussion on the origin of the causal agent of VL in the Americas and the Mediterranean basin remains opened. Probably, there will be much debate and speculations. But perhaps we will never know the true origin of the parasite. This is a theoretical viewpoint. Nevertheless, even though we discovered that L. infantum have been imported from the Americas (and not the opposite), this name must be maintained because it was first described. It is the law of priority - a basic principle of zoological nomenclature. If two names refer to the same taxon, the older one is the correct one. Forgetting this, we are either forgetting or neglecting the International Code of Zoological Nomenclature.

Based on different approaches (Momen et al. 1987, Maurício et al. 1999), L. infantum and L. chagasi are not clearly distinguished at the species level. A combined analysis of RAPD data with polymerase chain reactionrestriction fragment length polymorphism (PCR-RFLP) data from the internal transcribed spacer (ITS) of the ribosomal genes and from the mini-exon genes has shown that the degree of diversity among the L. infantum and $L$. chagasi strains is lower than that found within $L$. donovani strains (Maurício et al. 2000). Thus, shall we separate these L. donovani strains into new species or subspecies? What shall we do?

The separation of L. chagasi and L. infantum into two subspecies is, in part, acceptable. However, the subspeciation of L. infantum has obvious implications for the current classification of the genus Leishmania, in which there is no subspecies. Indeed, a reclassification of the genus would be required soon, with the inclusion of other subspecies, based on the same criteria used for the separation of $L$. infantum strains. Thus, in my view, $L$. infantum and L. chagasi must be regarded as synonymous, until a new classification for the genus Leishmania is proposed. Finally, by the law of priority (the prior name prevails) the name L. infantum is the valid name, even for causal agent of VL in the Americas. For didactic purposes only, the name L. chagasi should be given in brackets after the name $L$. infantum, i.e., 'L. infantum $(=L$. chagasi)', when we are referring to the parasite isolated from that area.

\section{REFERENCES}

Alvar J, Canavate C, Molina R, Moreno J, Nieto J 2004. Canine leishmaniasis. Adv Parasitol 57: 1-88.

Cunha AM 1938. Experimental infections in American visceral leishmaniasis. Mem Inst Oswaldo Cruz 33: 581-616.

Cunha AM, Chagas E 1937. New species of protozoa of the genus Leishmania pathogenic to man Leishmania chagasi 
n. sp previous note. Hospital (Rio de Janeiro) 11: 3-9.

Desjeux P 2004. Leishmaniasis: current situation and new perspectives. Comp Immunol Microbiol Infect Dis 27: 305318.

Dujardin JC 2005. Risk factors in the spread of leishmaniases: towards integrated monitoring? Trends in Parasitol 22: 4-6.

Ellis JT, Crampton JM 1991. Differences between Leishmania (Leishmania) chagasi, L. (L.) infantum and $L$. (L.) donovani as shown by DNA fingerprinting. Mem Inst Oswaldo Cruz. 86: 479-481.

Gramiccia M, Smith DF, Angelici MC, Ready PD, Gradoni L 1992. A kinetoplast DNA probe diagnostic for Leishmania infantum. Parasitology 105: 29-34.

Lainson R, Rangel E 2005. Lutzomyia longipalpis and the ecoepidemiology of American visceral leishmaniasis, with particular reference to Brazil - A Review. Mem Inst Oswaldo Cruz, 100: 811-827.

Lainson R, Shaw JJ 1987. Evolution, classification and geographic distribution. In W Peters, R Killick-Kendrick (eds), The Leishmaniases in Biology and Medicine, Vol. 1, Academic Press, London, p. 1-120.

Killick-Kendrick R 1985. Some epidemiological consequences of the evolutionary fit between leishmaniae and their phlebotomine vectors. Bull Soc Path Exot 78: 747-755.

Mauricio IL, Howard MK, Stothard JR, Miles MA 1999. Genetic diversity in the Leishmania donvani complex. Parasitology 119: 237-246.

Mauricio IL, Stothard JR, Miles MA 2000. The strange case of Leishmania chagasi. Parasitol Today 16: 188-189.

Momen H, Grimaldi Jr G, Deane LM 1987. Leishmania infantum, the aetiological agent of American visceral leishmaniasis (AVL)? Mem Inst Oswaldo Cruz, 82: 447-448.

Nicolle CJ 1908. Sur trois cas d'infection splénique infantile à corps de Leishman observés en Tunisie. Arch Inst Pasteur Tunis 3: 1-26.

Palatnik CB, Previato JO, Mendonça-Previato L, Borojevic R 1990. A new approach to the phylogeny of Leishmania: species specificity of glycoconjugate ligands for promastigote internalization into murine macrophages. Parasitol Res 76: 289-293.

Rioux JA, Lanotte G, Serres E, Pratlong F, Bastien P, Perieres J 1990. Taxonomy of Leishmania. Use of isoenzymes. Suggestions for a new classification. Ann Parasitol Hum Comp 65: 111-125.

Santoro F, Lemesre JL, Rizvi FS, Afchain D, Sadogirsky M 1986. Spécificité au niveau de protéines de surface des promastigotes de Leishmania donovani (Laveran et Mesnil, 1903), Leishmania infantum Nicolle, 1908 et Leishmania chagasi Cunha et Chagas, 1937. In JA Rioux (2-6 July, 1984). Leishmania. Taxonomie et Phylogenése. Aplications eco-Épidemiologiques. Montpellier, France: Colloque Internat, IMMEE, p. 71-76.

\section{REPLY}

We entirely agree with Dr Filipe Torres-Dantas' advice that the law of priority in the use of scientific names must not be forgotten or ignored, and this is evident by our correct use of the subspecific names Leishmania infantum infantum and L. infantum chagasi in our review paper. In addition, however, we feel that when a number of differences have been shown to exist between two otherwise similar organisms (most probably an indication of the continuing process of speciation) these, too, should not be forgotten or ignored. It is for this reason that we prefer not to refer to the neotropical agent of visceral leishmaniasis simply as L. infantum (=L. chagasi). The symbol $=$ suggests that the neotropical and Old World parasites are identical which, in view of the afore-mentioned "minor" differences, they clearly are not. Incidentally, one might ask Dr Torres-Dantas for his definition of a "minor" difference. Is, for example, the finding that a monoclonal antibody against the promastigotes of one of the parasites does not recognize those of the other (Santoro et al. 1986) a "minor" difference?

Subspecific names have been extensively and acceptably used in the taxonomy of a great many protozoan and metazoan organisms. They were for long used in the taxonomy of the leishmanias, with names such as $L$. braziliensis braziliensis, L. braziliensis guyanensis, L. mexicana amazonensis etc, until improving methods of identification and separation resulted in the elevation of these parasites to specific rank. However, there is now an increasing awareness of "minor" differences among isolates of some of these parasites (conveniently referred to as serodemes and zymodemes) and it may well be that they will be considered as subspecies in the future.

With regards to Dr Torres-Dantas' concern that the use of the subspecific names $L$. infantum infantum and $L$. infantum chagasi might necessitate the use of other subspecific names within the L. donovani complex, this is for individual taxonomists to decide. The basic foundation for the classification of the Leishmania species is unlikely to be severely disrupted by the addition of some subspecific names, and at least these will indicate the close relationship of certain parasites and effectively emphasise the role of speciation in producing the "minor" differences he refers to. 